\title{
Soil Removal Efficacy of Catholyte on Polyamide 6.6 Fabric
}

\author{
Natasha van Heerden, Hester JH Steyn, Robert Schall \\ University of the Free State, Bloemfontein, South Africa
}

\begin{abstract}
This study determined the detergency properties of Catholyte, an electrochemically activated medium, on polyamide 6.6 as a possible alternative to conventional laundering detergents. Undyed polyamide 6.6 was used and soiled with keltex, corn starch, mineral oil, oleic acid, morpholine, vegetable fat, butanol, solvesso 150 and water. Some soiled fabric was retained as control and not laundered. Soiled fabric was laundered at $30{ }^{\circ} \mathrm{C}$ as well as $40{ }^{\circ} \mathrm{C}$ with either, distilled water, Catholyte, non-phosphate detergent, a 50/50 solution of Catholyte and non-phosphate detergent, or a 50/50 solution of Catholyte and phosphate detergent. Data were analyzed descriptively by using analysis of variance (ANOVA), which fitted the factors of treatment and temperature, as well as all two-factor interactions between these variables. A probability value of 0.05 or less indicated significance. Catholyte was effective in removing soil and reached a $\triangle E^{*}$ value of 59.30, but was statistically different from the phosphate detergent. Temperature did not have a significant effect on soil removal from the fabric, but the interaction with a treatment had significant effects. Treatment alone had a significant soil removal effect on the fabric. Thus, the temperature was dependent on an interaction with the treatment. The non-phosphate detergent was efficient in removing soil from the fabric and slightly more efficient than either 50/50 Catholyte solution. The 50/50 Catholyte/non-phosphate detergent solution was slightly less effective than its phosphate containing counterpart. When considering the interaction between treatment and temperature, the 50/50 Catholyte/phosphate and 50/50 Catholyte/non-phosphate solutions were more efficient at $40{ }^{\circ} \mathrm{C}$. Thus the interaction between the solution and higher temperature proved to be a better combination. This was also the case for the Catholyte and the non-phosphate wash liquors. Catholyte, an environmentally friendly washing agent, is an attractive alternative to conventional laundry detergents because it removes soil efficiently from polyamide 6.6 fabric.
\end{abstract}

Keywords: electrochemical activation, Catholyte, soil removal, polyamide 6.6

\section{Introduction}

Soil removal plays a vital role in caring for fabrics and effective soil removal contributes to maintaining the fabric in a good condition for prolonged use (Kadolph, 2007). Soil accumulation on textile products is one of the main factors that cause fabrics to deteriorate (Collier \& Tortora, 2001); food messed on fabric is such an example.

Natasha van Heerden, M.Sc Home Economics, Department of Consumer Sciences, Faculty of Natural and Agricultural Sciences, University of the Free State.

Hester JH Steyn, Ph.D., Professor, Department of Consumer Sciences, Faculty of Natural and Agricultural Sciences, University of the Free State.

Robert Schall, Ph.D., Professor, Department of Mathematical Statistics and Actuarial Science, Faculty of Natural and Agricultural Sciences, University of the Free State.

Correspondence concerning this article should be addressed to Natasha van Heerden, University of the Free State 205 Nelson Mandela Drive Park West Bloemfontein. E-mail: vanheerdenn@ufs.ac.za. 
Insects, not usually attracted to fabric, are attracted because food soiled fabrics contain organic substrates. Dirt that has been rubbed into the fabric causes an increase in the abrasion of the yarns, which eventually causes the fibres to break and damages the fabric (Collier \& Tortora, 2001).

A wide variety of soils from different origins can be found in textile materials (Johansson \& Somasundaran, 2007) and consists of different ingredients or materials (Collier \& Tortora, 2001). Soils can be categorized into water-soluble components, hydrophobic soils, particulates, bleachable stains, and enzyme-sensitive stains. Each of these requires different techniques for effective removal (Johansson \& Somasundaran, 2007). Organic acids, mineral acids, alkaline substances, blood, starches, and sugars are all materials that can be dissolved in cool or warm water with the aid of a detergent. These soil stains are usually easily cleaned, but sometimes special stain-removal techniques or substances are needed (Collier \& Tortora, 2001). Insoluble soils such as grease, oil, or film may bind to the fabric by physical attraction. Water alone cannot remove insoluble soils and special materials or solutions are necessary to assist in the removal process (Collier \& Tortora, 2001).

The degree to which a textile fabric can be soiled is related to the hydrophilic nature of the fibres, as well as their negative charge. The electrostatic charge on the fibres, the smoothness of the yarn and the fabric surface also contribute to the soil resistance of a textile fabric (Ilec, Simončič, \& Hladnik, 2009).

Polyamide 6.6, or nylon, is a popular textile with favorable properties (Kumar \& Gupta, 1998) that include strength, resistance, stability, and versatility in stiffness. Polyamide 6.6 is resistant to alkalis, but will hydrolyze and weaken after frequent alkali exposure (Kadolph, 2007; Johnson \& Cohen, 2010). Fabrics made from polyamide 6.6 are machine washable at $30{ }^{\circ} \mathrm{C}$ or $40{ }^{\circ} \mathrm{C}$ and gentle agitation prevents wrinkling (Collier \& Tortora, 2001; Ruscher, 2004; Kadolph, 2007).

The efficiency of any laundering process is dependent on a few factors, namely, the chemical structure of the textile fabric as well as the construction thereof, the type of soil, the structure and concentration of the surfactant and all the other ingredients present in a detergent formulation. The conditions in which the laundering takes place are also of great importance (Ilec, Simončič, \& Hladnik, 2009).

Laundry detergents made from non-renewable chemicals (Bajpai \& Tyagi, 2007) are commonly used washing agents (Hollis, 2002; Cameron, 2007), and enter the water system as effluent (Stalmans, Matthijs, \& De Oude, 1991). The large amount of laundry chemical effluent has a detrimental effect on the water system and it is important that fresh water supplies are protected (Bajpai \& Tyagi, 2007). Phosphate, one of the detergent ingredients, causes eutrophication. Eutrophication might cause aquatic life to die and the water to become toxic (Köhler, 2006).

In 2007, the United States had no phosphate containing detergents, but $68 \%$ of the European and $50 \%$ of the Canadian detergents contained phosphate (Bajpai \& Tyagi, 2007). On November 4, 2010, the European Commission published a regulation that limited phosphate containing compounds in laundry detergents to $0.5 \%$ of the total weight of the detergent as of January 1, 2013 (Ovrebekk, 2010). Latin America and some of the Pacific region countries still use phosphate-based detergents (Bajpai \& Tyagi, 2007). Phosphate may soon be banned throughout the world, hence, alternative detergents need to be investigated.

The development of electrochemically activated aqueous media over the last two decades has become quite a phenomenon (Lobyshev, 2007). The aqueous media is activated by passing water through the electrochemical cells, anode, and cathode. The electrodes activate two different media, each with unique properties and 
characteristics (Thantsha \& Cloete, 2006). Catholyte is an alkaline medium and is synthesized in the cathode (Bakhir, 2005). Catholyte may provide an acceptable alternative to other solvents that are generally used (Thantsha \& Cloete, 2006) and have been used in a range of applications including medicine, agriculture, microbiology, and the food industry (Lobyshev, 2007), but not in textiles.

Water and sodium chloride are used for the production of Catholyte. The production requires minimal energy, the apparatus is simple, no effluent or gas is produced and unused Catholyte reverts to normal water after a few days. Production is also on site, which precludes packaging and transport, all factors that make the product environmentally acceptable and sustainable.

Catholyte as an alternative to laundry detergents is promising but the feasibility thereof needs to be established. Therefore, this study evaluated the soil removal efficacy of Catholyte on polyamide 6.6 fabric. Additionally, the soil removal efficacy of non-phosphate detergent as well as a 50/50 solution of Catholyte and non-phosphate detergent, and a 50/50 solution of Catholyte and phosphate detergent were evaluated.

\section{Materials and Methods}

Undyed polyamide 6.6 fabric (style STC TF \#361) was used in the study and soiled. The components for the soiling of a standard soiled fabric are keltex, corn starch, mineral oil, oleic acid, morpholine, vegetable fat, butanol, solvesso 150, and water. Some soiled fabric was retained as control and not laundered.

Standard soiled polyamide 6.6 fabric was laundered (AATCC 61-2009) for five cycles. The soiled fabric was laundered with Catholyte, detergent, and distilled water at a temperature of $30{ }^{\circ} \mathrm{C}$ and $40{ }^{\circ} \mathrm{C}$. The Catholyte was prepared by the electrolysis of a $5 \% \mathrm{NaCl}$ concentration in distilled water solution. The electrolysis was carried out under uniform conditions of a continuous electric current of 12 ampere and pressure of 75 kilo-Pascal and continued until the Catholyte reached $\mathrm{pH}$ 12-13. The Catholyte was used within eight hours of preparation. The ECE Phosphate Reference Detergent Type B without optical brightener (James H. Heal \& Co. Ltd.) was used at a concentration of $0.15 \%$ per $150 \mathrm{~mL}$ wash liquor.

A colorimeter and the CIE $1976 \mathrm{~L} \mathrm{a}^{*} \mathrm{~b} *$ colour scale formula were used to calculate the difference in shade (AATCC 135-1985) before and after soil removal. Soil was assessed as a colour on the textile fabric and soil removal was quantitatively measured as colour change. The differences in colour were expressed as a numerical value by calculating delta-E ( $\left.\triangle E^{*}\right)$. The colorimetrically determined numerical values were compared with the numerical value obtained before soil removal (Ilec, Simončič, \& Hladnik, 2009).

Additionally, the soil removal efficacy of ECE Non-Phosphate Reference Detergent Type B without optical brightener (James H. Heal \& Co. Ltd.) as well as a 50/50 solution of Catholyte and non-phosphate detergent and a 50/50 solution of Catholyte and phosphate detergent was tested. The same procedure as above was followed.

Data from the soiled fabric laundered with Catholyte, detergent, and distilled water were analysed by using analysis of variance (ANOVA). The ANOVA model fitted the factors treatment (Catholyte, detergent, distilled water) and temperature $\left(30{ }^{\circ} \mathrm{C}, 40{ }^{\circ} \mathrm{C}\right)$, as well as all two-factor interactions between these variables. $P$-values for all effects in the model were obtained from the ANOVA. Furthermore, least squares means for all treatments and temperatures and combinations of these two factors were calculated with their standard errors. Estimates of the differences between least squares means, with associated $P$-values were also reported. All analyses were carried 
out by using the GLM procedure of the SAS software package (SAS Institute Inc., 2004). A probability value of 0.05 or less indicated significance. Descriptive statistics were used to summarize data from soil removal efficacy of the non-phosphate detergent 50/50 Catholyte and non-phosphate detergent solution and the 50/50 Catholyte and phosphate detergent solution.

\section{Results and Discussion}

The soil removal efficacy of Catholyte, phosphate detergent, and distilled water is illustrated in Figure 1. The $\triangle E^{*}$ value of the soiled polyamide fabric before exposure to any treatment processes was 42.30 . Laundering the soiled polyamide with the phosphate detergent was effective and a $\triangle \mathrm{E}^{*}$ value of 64.92 was obtained. Phosphate is known to be an effective builder in detergents (Johansson \& Somasundaran, 2007), therefore these results were expected.

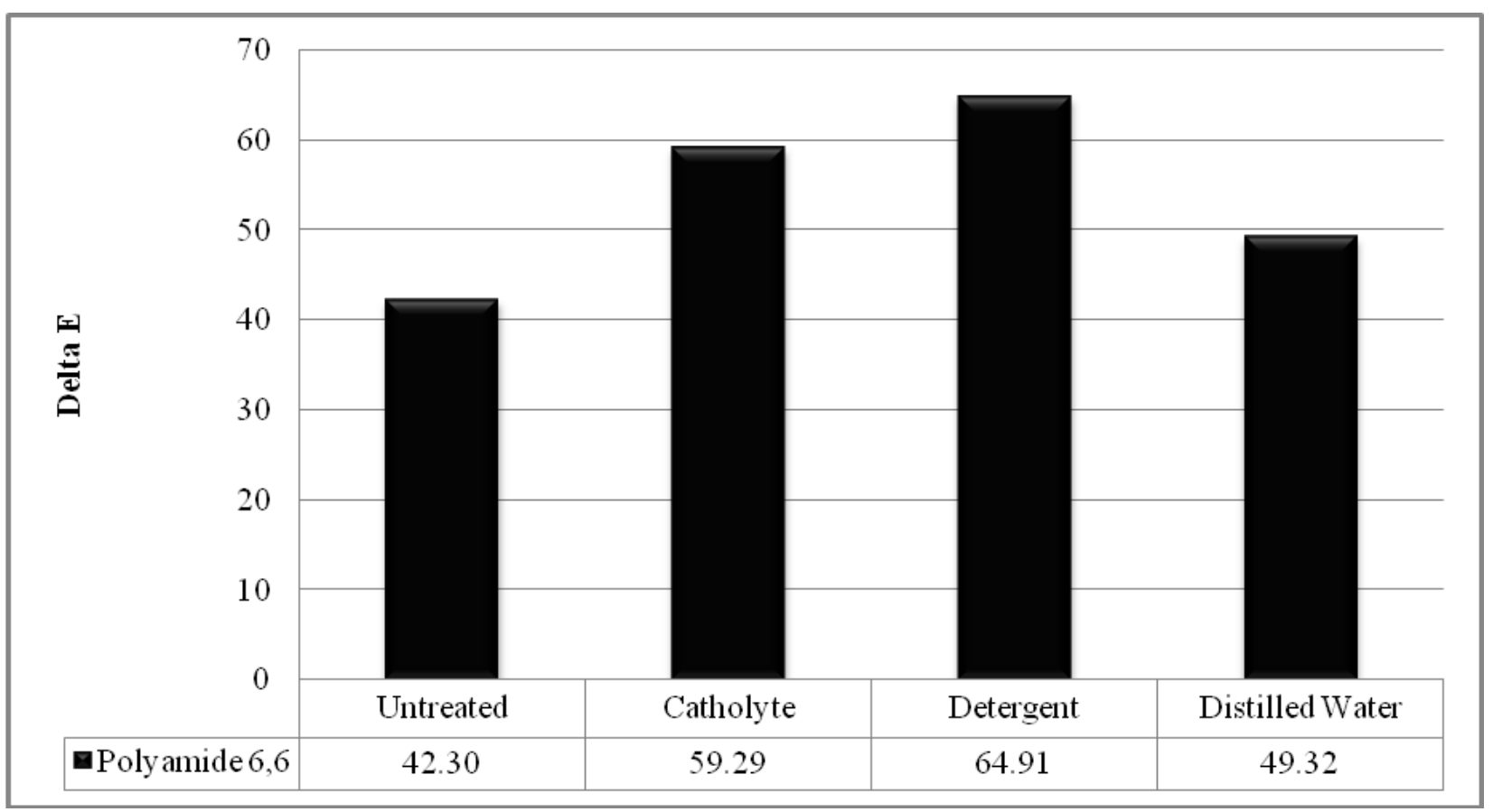

Figure 1. The efficacy of Catholyte, detergent, and distilled water to remove soil from polyamide 6.6 fabric.

Catholyte was effective enough in removing soil and reached a $\triangle \mathrm{E}^{*}$ value of 59.30. Although significantly different (see Table 1) from the phosphate detergent, the Catholyte performed well enough to be considered as a promising alternative. The distilled water $\triangle E^{*}$ value of 49.32 once again confirmed that water alone could not remove soil efficiently although it is an essential part of the laundering process. Significant differences in the soil removal efficacy were found when distilled water was compared to phosphate detergent and Catholyte (see Table 1).

The multiple ways in which built phosphate detergent removes soil explain the better performance of the phosphate detergent above Catholyte. The phosphate detergent binds ions, buffers the $\mathrm{pH}$, and breaks up the soil (Bajpai \& Tyagi, 2007). The Catholyte lacks the pH buffering because a builder is not part of the composition of a Catholyte, and this may explain the decreased efficacy compared to phosphate detergent. 
Table 1

The Soil Removal Efficacy of Catholyte, Phosphate Detergent and Distilled Water From Polyamide 6.6

\begin{tabular}{|c|c|c|c|c|c|c|}
\hline Soil removal & & $\begin{array}{l}\text { Delta-E value } \\
\left(\triangle E^{*}\right)\end{array}$ & Difference & $P$-Value & Difference & $P$-Value \\
\hline No treatment & & 42.30 & & & & \\
\hline \multirow[t]{4}{*}{ Treatment } & & & \multicolumn{2}{|c|}{ (Relative to distilled water) } & \multicolumn{2}{|c|}{ (Catholyte relative to phosphate detergent) } \\
\hline & Catholyte & 52.29 & 9.97 & $<0.0001^{*}$ & 5.62 & $<0.0001^{*}$ \\
\hline & Phosphate detergent & 64.91 & 15.59 & $<0.0001^{*}$ & & \\
\hline & Distilled water & 49.32 & & & & \\
\hline \multirow[t]{3}{*}{ Temperature } & & & \multicolumn{2}{|c|}{ (Relative to $40{ }^{\circ} \mathrm{C}$ ) } & & \\
\hline & $30{ }^{\circ} \mathrm{C}$ & 57.62 & 0.45 & 0.2627 & & \\
\hline & $40{ }^{\circ} \mathrm{C}$ & 58.06 & & & & \\
\hline
\end{tabular}

Note. ${ }^{*}$ Statistically significant.

Slightly more soil was removed from polyamide 6.6 fabric at $40{ }^{\circ} \mathrm{C}$ (see Figure 2). There was, however, no significant difference ( $P$-value 0.2627 ) between soil removal at $30{ }^{\circ} \mathrm{C}$ and soil removal at $40{ }^{\circ} \mathrm{C}$ (see Table 1 ). Thus temperature did not have a significant influence on the soil removal from the polyamide 6.6 fabric.

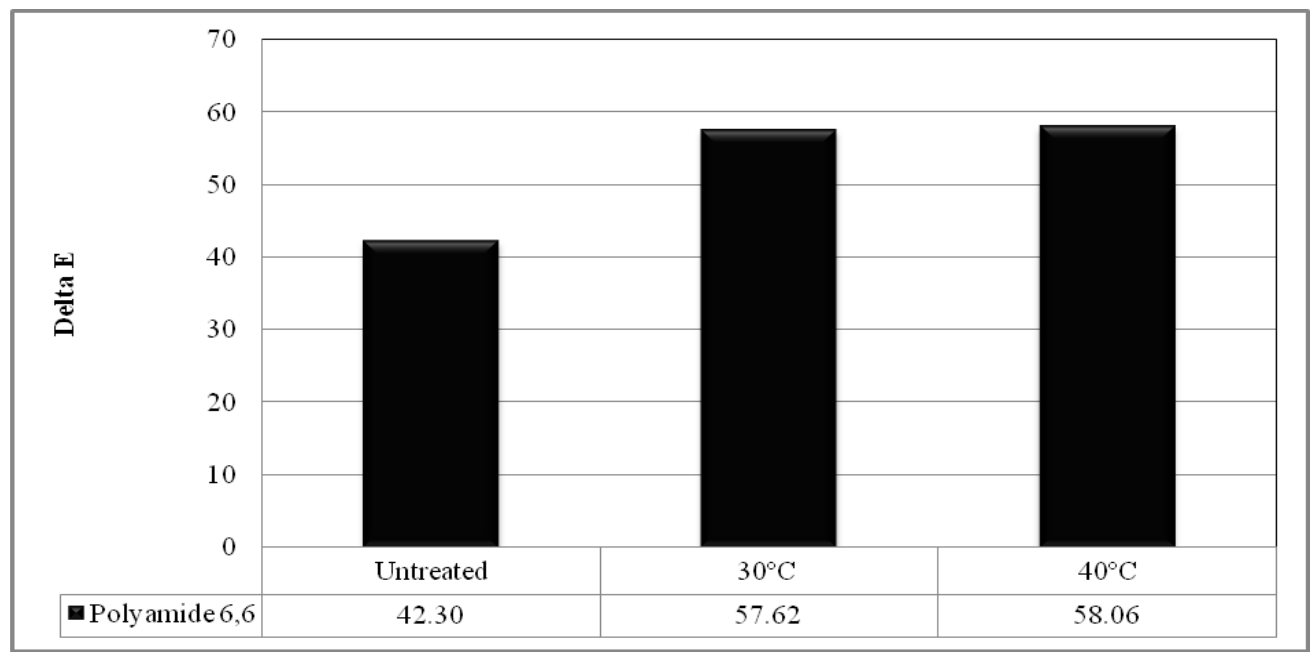

Figure 2. The influence of temperature on soil removal from polyamide 6.6 fabric.

The interaction that took place between the temperature and the treatment with which the soiled fabric was laundered, had a significant influence on the soil removal of the fabric (see Table 2). The $\triangle \mathrm{E}^{*}$ value means are summarized in Figure 3.

Laundering the polyamide 6.6 fabric with phosphate detergent at $30{ }^{\circ} \mathrm{C}$ seemed to be the most effective means for removing soil. Laundering the fabric with detergent at $40{ }^{\circ} \mathrm{C}$ was also effective and there was no significant difference between laundering at $40{ }^{\circ} \mathrm{C}$ and laundering at $30{ }^{\circ} \mathrm{C}$. The $\triangle \mathrm{E}^{*}$ value was slightly lower when laundered at $40{ }^{\circ} \mathrm{C}$.

The soil removal of the polyamide 6.6 fabric laundered with Catholyte at $30{ }^{\circ} \mathrm{C}$ was less effective than when laundered at $40{ }^{\circ} \mathrm{C}$. Laundering the fabric at either $30{ }^{\circ} \mathrm{C}$ or $40{ }^{\circ} \mathrm{C}$ using phosphate detergent was still significantly more effective than with Catholyte or distilled water (see Figure 3 and Table 2). Laundering the polyamide 6.6 fabric with distilled water at $30{ }^{\circ} \mathrm{C}$ and $40{ }^{\circ} \mathrm{C}$ proved to be the least effective. 


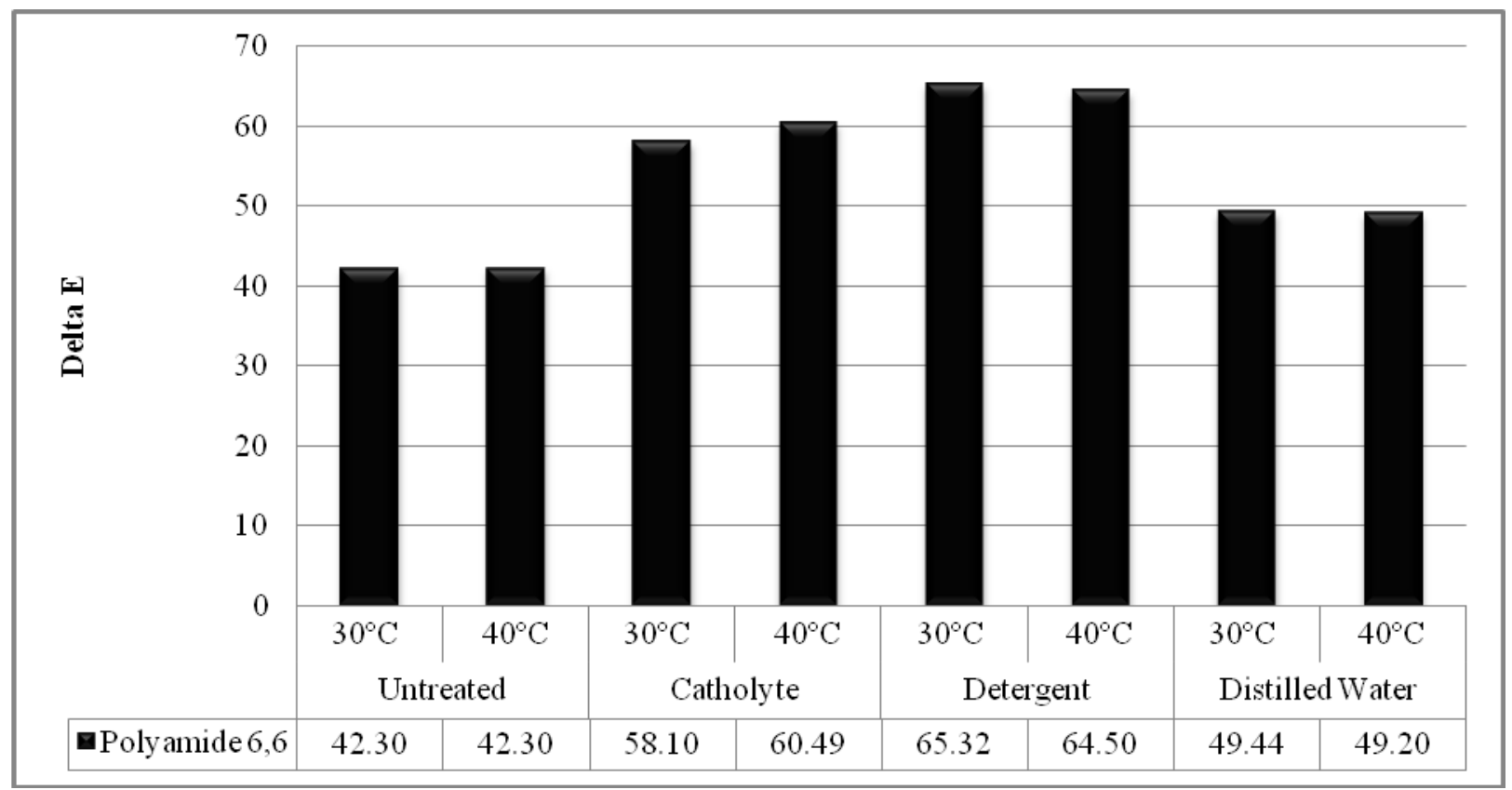

Figure 3. Influence of the treatment/temperature interaction on the soil removal from polyamide 6.6 fabric.

Therefore temperature alone does not have a significant effect on soil removal from the polyamide 6.6 fabric, but the interaction with a treatment has significant effects. Treatment alone has a significant soil removal effect on the polyamide 6.6 samples. This means that the cleaning efficacy of the treatment is not dependent on the temperature but rather that the temperature is dependent on an interaction with the treatment.

Table 2

P-Values of the Interaction Between Temperature and Treatment for the Soil Removal From Polyamide 6.6 Fabric

\begin{tabular}{|c|c|c|c|c|c|c|}
\hline$P$-Values & $\begin{array}{l}\text { Catholyte } \\
30{ }^{\circ} \mathrm{C}\end{array}$ & $\begin{array}{l}\text { Catholyte } \\
40{ }^{\circ} \mathrm{C}\end{array}$ & $\begin{array}{l}\text { Phosphate } \\
\text { detergent } 30{ }^{\circ} \mathrm{C}\end{array}$ & $\begin{array}{l}\text { Phosphate } \\
\text { detergent } 40{ }^{\circ} \mathrm{C}\end{array}$ & $\begin{array}{l}\text { Distilled water } \\
30{ }^{\circ} \mathrm{C}\end{array}$ & $\begin{array}{l}\text { Distilled water } \\
40{ }^{\circ} \mathrm{C}\end{array}$ \\
\hline Catholyte $30{ }^{\circ} \mathrm{C}$ & & $0.0007^{*}$ & $<0.0001^{*}$ & $<0.0001^{*}$ & $<0.0001^{*}$ & $<0.0001^{*}$ \\
\hline Catholyte $40{ }^{\circ} \mathrm{C}$ & $0.0007^{*}$ & & $<0.0001^{*}$ & $<0.0001^{*}$ & $<0.0001^{*}$ & $<0.0001^{*}$ \\
\hline Phosphate detergent $30{ }^{\circ} \mathrm{C}$ & $<0.0001^{*}$ & $<0.0001^{*}$ & & 0.2325 & $<0.0001^{*}$ & $<0.0001^{*}$ \\
\hline Phosphate detergent $40{ }^{\circ} \mathrm{C}$ & $<0.0001^{*}$ & $<0.0001^{*}$ & 0.2325 & & $<0.0001^{*}$ & $<0.0001^{*}$ \\
\hline Distilled water $30{ }^{\circ} \mathrm{C}$ & $<0.0001^{*}$ & $<0.0001^{*}$ & $<0.0001^{*}$ & $<0.0001^{*}$ & & 0.7264 \\
\hline Distilled water $40{ }^{\circ} \mathrm{C}$ & $<0.0001^{*}$ & $<0.0001^{*}$ & $<0.0001^{*}$ & $<0.0001^{*}$ & 0.7264 & \\
\hline
\end{tabular}

Note. "Statistically significant.

The additional evaluation of the soil removal efficacy of non-phosphate detergent as well as a 50/50 solution of Catholyte and non-phosphate detergent and a 50/50 Catholyte and phosphate detergent solution was done because of the decreasing use of phosphate containing detergents and increased government legislation and regulation. The non-phosphate detergent was quite efficient in removing soil from the polyamide 6.6 fabric (see Figure 4) and slightly more efficient than either 50/50 Catholyte solution. The 50/50 Catholyte/non-phosphate detergent solution was slightly less than its phosphate containing counterpart. Taking these results into consideration, Catholyte would still be the best alternative to phosphate containing detergents. 


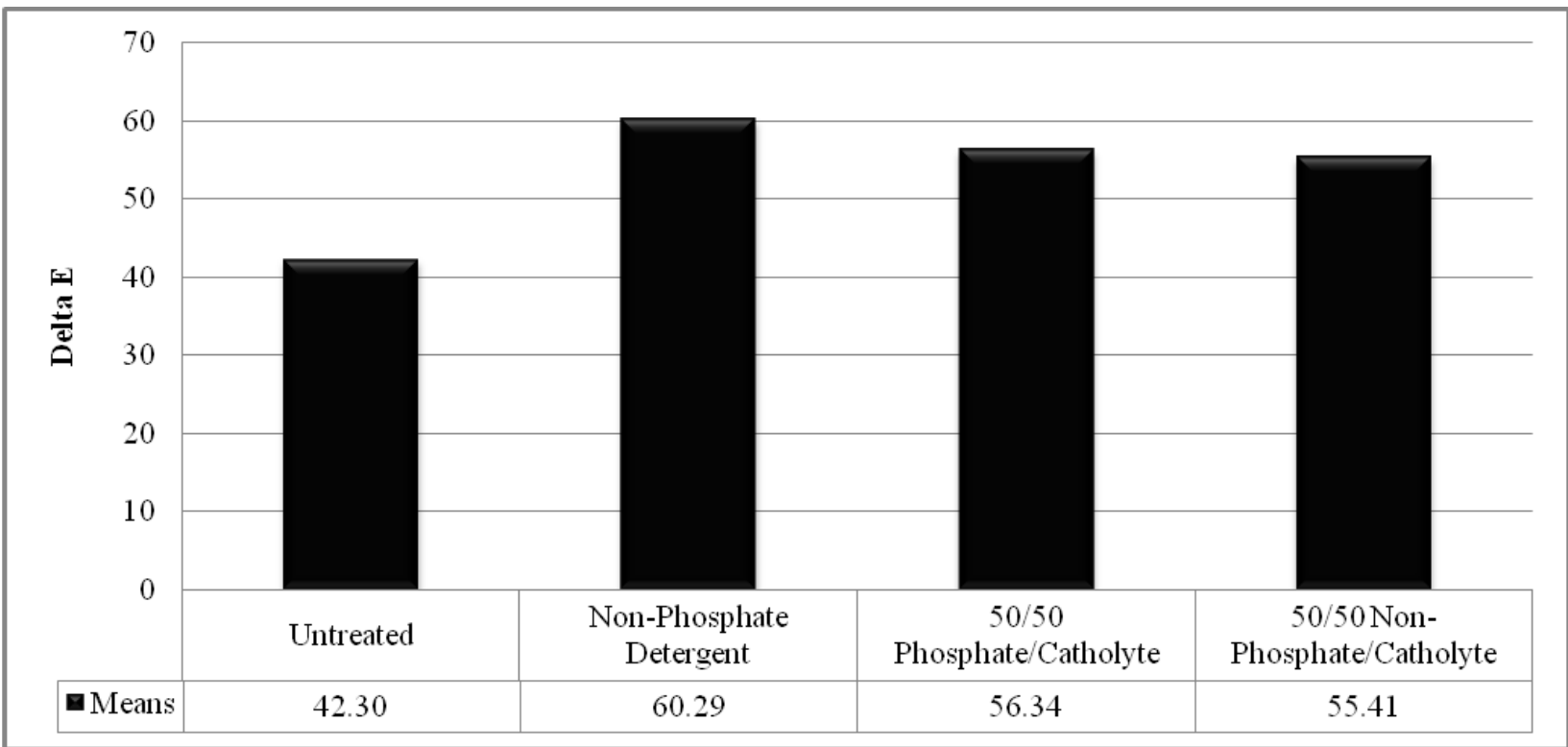

Figure 4. Soil removal efficacy from polyamide 6.6 using non-phosphate detergent, 50/50 solution of Catholyte and phosphate detergent, and 50/50 solution of Catholyte and non-phosphate detergent.

When considering the interaction between treatment and temperature in Figure 5, the 50/50 Catholyte/phosphate and 50/50 Catholyte/non-phosphate solutions were more efficient at $40{ }^{\circ} \mathrm{C}$. Thus the interaction between the solution and higher temperature proved to be a better combination. This was also the case for the Catholyte and the non-phosphate wash liquors.

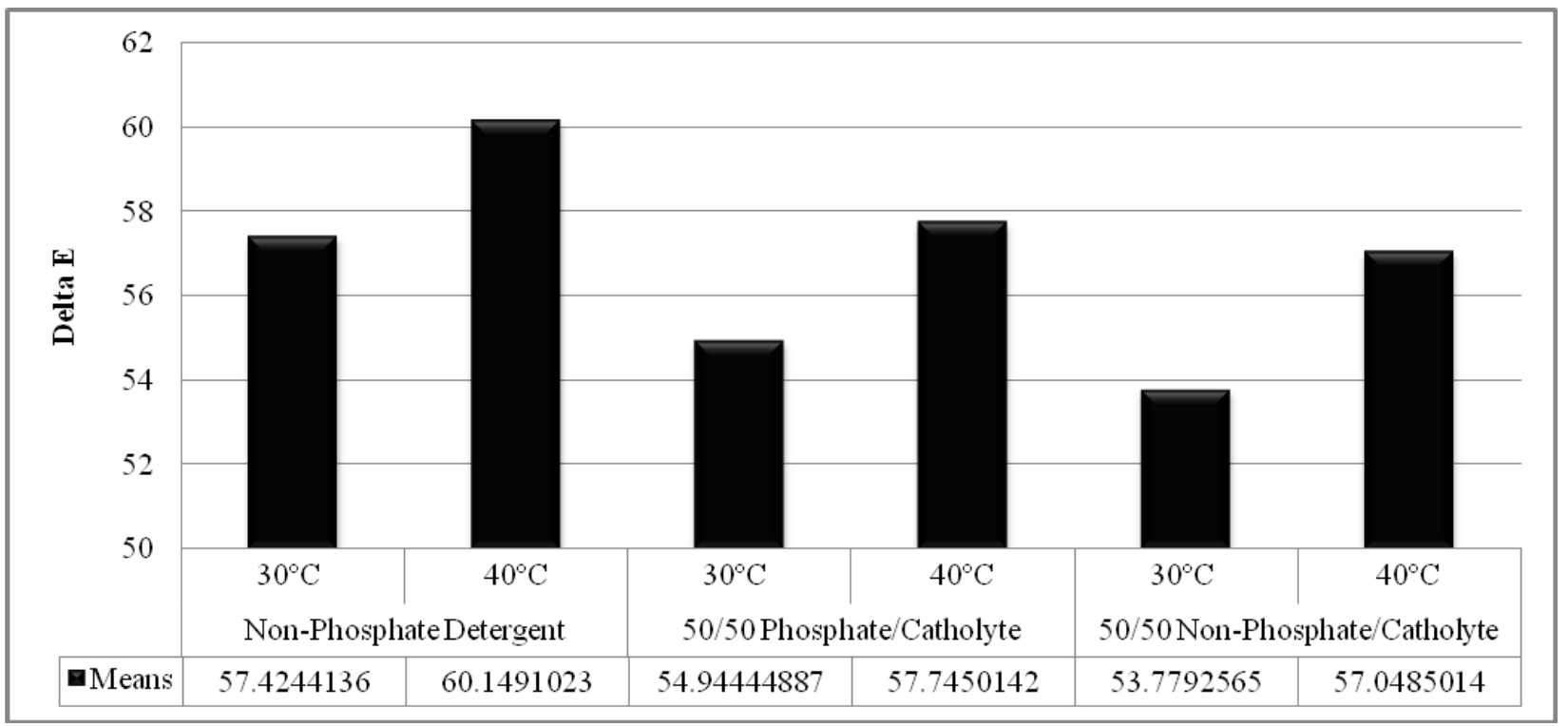

Figure 5. Treatment/temperature interaction on the soil removal from polyamide 6.6.

\section{Conclusions and Recommendation}

Catholyte is an environmentally friendly washing agent that is an attractive alternative to conventional laundry detergents because it removes soil efficiently from polyamide 6.6 fabric. More research to find ways in which the Catholyte performance can be improved needs to be done. The laundering of textile fabrics with 
electrochemically activated water would contribute to the more green approach of consumers and manufacturers. However, it is necessary to do a life cycle assessment of the product for a comparison with conventional laundry detergents and to communicate certain important aspects to consumers.

\section{References}

Bajpai, D., \& Tyagi, V. K. (2007). Laundry detergents: An overview. Journal of Oleo Science, 56, 327-340.

Bakhir, V. M. (2005). Electrochemical activation, VitoldBakhir institute. Retrieved from http://www.vbinstitute.org/terms/.html

Cameron, B. A. (2007). Laundering in cold water: Detergent considerations for consumers. Family and Consumer Sciences Research Journal, 36, 151-162.

Collier, B. J., \& Tortora, P. G. (2001). Understanding textiles (6th ed.). Upper Saddle River: Prentice Hall.

Hollis, G. (2002). Surfactants in the global world. Focus on Surfactants, 1, 1-2.

Ilec, E., Simončič, B., \& Hladnik, A. (2009). Evaluation of surfactant detergency using statistical analysis. Textile Research Journal, 79, 318-325.

Johansson, I., \& Somasundaran, P. (2007). Handbook for cleaning/decontamination of surfaces (Vol. 2). Amsterdam: Elsevier.

Johnson, I., \& Cohen, A. C. (2010). J. J. Pizzuto’s fabric science (9th ed.). New York: Fairchild Books.

Kadolph, S. J. (2007). Textiles. New Jersey: Pearson Education Ltd..

Köhler, J. (2006). Detergent phosphates: An EU policy assessment. Journal of Business Chemistry, 3, 15-30.

Kumar, A., \& Gupta, R. K. (1998). Fundamentals of polymers. New York: McGraw-Hill.

Lobyshev, V. I. (2007). Electrochemically activated water. The Second Annual Conference on the Physics, Chemistry, and Biology of Water. West Dover, Vermont: Vermont Photonics Inc..

Ovrebekk, H. (2010). EC proposes ban on the use of phosphates in laundry detergents. ICIS News. Retrieved from http://www.icis.com/Articles/2010/11/04/9407516/ec-proposes-ban-on-the-use-of-phosphates-in-laundry-detergents.html

Ruscher, T. (2004). Polyamide-Aversatile fiber that places high demands on textile finishers. Asian Textile Business, 591, 61-63.

SAS Institute Inc.. (2004). SAS/STAT 9.1 User's guide. Chapter 32: The GLM procedure (pp. 1731-1906). Cary, N.C.: SAS Institute Inc..

Stalmans, M., Matthijs, E., \& De Oude, N. T. (1991). Fate and effect of detergent chemicals in the marine and estuarine environment. Water Science and Technology, 24, 115-126.

Thantsha, M. S., \& Cloete, T. E. (2006). The effect of sodium chloride and sodium bicarbonate derived anolytes, and anolyte-catholyte combination on biofilms. Water SA, 32, 237-242. 